\title{
Current outcomes of one-stage surgical correction for Berry syndrome
}

Renjie Hu, MD, Wen Zhang, MD, Xinrong Liu, MD, Wei Dong, MD, Hongbin Zhu, MD, and Haibo Zhang, MD, PhD

\section{ABSTRACT}

Objectives: Berry syndrome is a combination of distal aortopulmonary window (APW), aortic origin of the right pulmonary artery (RPA), intact ventricular septum, and interrupted aortic arch. We present here our current experience of primary repair of this syndrome with the goal of optimizing treatment for this rare condition.

Methods: From January 2003 through December 2015, 16 infants with Berry syndrome underwent one-stage repair at Shanghai Children's Medical Center. Three different surgical correction techniques were used to repair the APW and aortic origin of the RPA, including intra-aortic baffle in 5, RPA detachment in 6, and RPA angioplasty with aortic cuff in 5 patients.

Results: The median age at repair was 90.5 days (range, 8-170 days). The interrupted aortic arch morphology was type A in 14 and type B in 2 patients. The APW morphology was type IIa in 4, type IIb in 10, and type III in 2 patients. Hospital death occurred in 2 patients, and death at follow-up occurred in one other patient. Three patients who previously underwent RPA angioplasty with aortic cuff required reoperation for aortic or RPA stenosis. Freedom from reoperation was $84.8 \%, 75.4 \%$, and $75.4 \%$, respectively at 1,5 , and 10 years after surgery.

Conclusions: One-stage repair of Berry syndrome has achieved acceptable outcomes. Reoperations mainly are related to aortic or RPA stenosis, and the reoperation rate is higher when RPA arterioplasty is performed with an aortic cuff. (J Thorac Cardiovasc Surg 2017;153:1139-47)

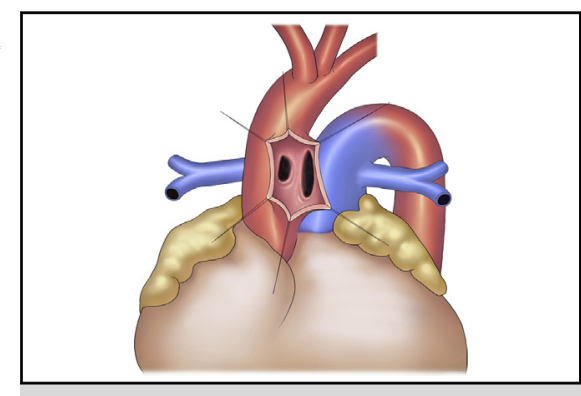

The anatomical characteristics of Berry syndrome.

\section{Central Message}

One-stage repair of Berry syndrome has achieved acceptable outcomes. The reoperation rate varies after different surgical techniques.

\section{Perspective}

Berry syndrome is an extremely rare condition, and most of the published literature is comprised of case reports. Our experience with 16 infants shows that one-stage repair has achieved acceptable outcomes. Reoperations mainly are related to aortic or RPA stenosis, and the reoperation rate is higher when RPA arterioplasty is performed with an aortic cuff.

See Editorial Commentary page 1148
The association of distal aortopulmonary window (APW), aortic origin of the right pulmonary artery (RPA), intact ventricular septum, and interruption or coarctation of the aortic isthmus was described as a syndrome by Teresa E. Berry in 1982. ${ }^{1}$ The Berry syndrome is extremely rare, and most of the published literature comprises case reports or includes patients in whom there is an association between

\footnotetext{
From the Department of Pediatric Cardiothoracic Surgery, Shanghai Children's Medical Center, Shanghai Jiaotong University School of Medicine, Shanghai, China. Drs Hu and Zhang contributed equally to this work.

Received for publication July 27, 2016; revisions received Nov 9, 2016; accepted for publication Nov 19, 2016; available ahead of print Jan 12, 2017.

Address for reprints: Haibo Zhang, MD, PhD, Department of Pediatric Cardiothoracic Surgery, Shanghai Children's Medical Center, Shanghai Jiaotong University School of Medicine, 1678 Dongfang Rd, Shanghai, China (E-mail: zhanghaibosh@126.com).

$0022-5223 / \$ 36.00$

Copyright (c) 2016 by The American Association for Thoracic Surgery

http://dx.doi.org/10.1016/j.jtcvs.2016.11.058
}

APW and an interrupted aortic arch (IAA). ${ }^{2-4}$ Until recently, the number of patients with Berry syndrome in the available literature was no greater than $40 .^{5}$

The anatomic characteristics mainly focus on the size and location of the APW, the origin of the RPA, and the type and range of IAA. Because of the large APW and the anomalous origin of the RPA from the aorta (AORPA), critical pulmonary hypertension appears early after birth. The RPA usually is dilated due to the consistent left-to-right shunt from the aorta, which also causes tracheal airway compression before surgery. The perfusion of the lower body is

Scanning this QR code will take you to a video for the article.

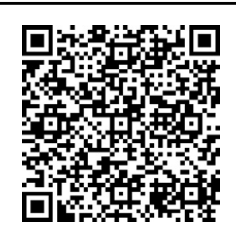




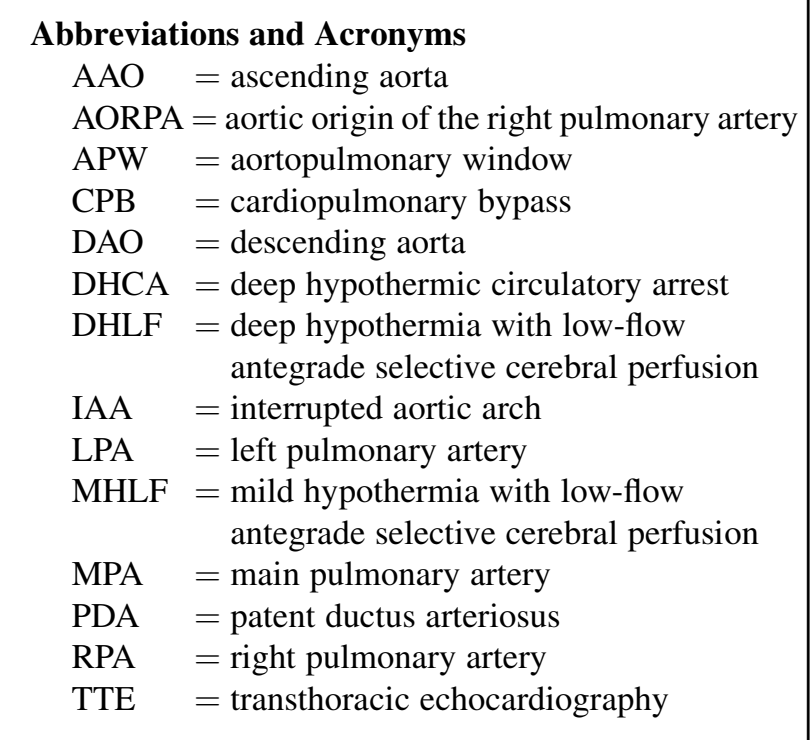

entirely from the patent ductus arteriosus (PDA) and depends on the communication between the aorta and pulmonary arteries through the APW. Therefore, early surgical correction in the neonatal period is recommended in these patients to protect the pulmonary vascular bed from irreversible hypertension and to restore normal perfusion of the lower body organs.

Three different methods of surgical correction have been described to repair the APW and AORPA, including intraaortic baffle, RPA detachment, and RPA angioplasty with aortic cuff. Because of the combination of these 2 congenital anomalies, surgical treatment seems to be more diverse and difficult when compared with what typically is necessary and used to repair these anomalies when they occur in isolation. There have been no large retrospective studies investigating the surgical outcomes to compare these 3 methods. Here, we summarize the comparison of the different one-stage surgical corrections and assess patient outcomes, including mortality, supravalvar aortic, and RPA stenosis over a longer follow-up period.

\section{PATIENTS AND METHODS}

Between January 2003 and December 2015, 16 infants with the diagnosis of Berry syndrome underwent one-stage complete repair at the Shanghai Children's Medical Center. The hospital ethics committee approved this study and waived the need for individual consent. Data were collected retrospectively from hospital records and outpatient clinics, as well as telephone follow-up.

\section{Preoperative Characteristics}

The diagnosis of Berry syndrome was made with transthoracic echocardiography (TTE), cardiac computed tomography, or magnetic resonance imaging in all patients, in addition to cardiac catheterization in 2 patients. The IAA morphology was specified according to the classification reported by Celoria and Patton. ${ }^{6}$ The APW type was based on the original classification of $\mathrm{Mori}^{7}$ and Berry's supplementary

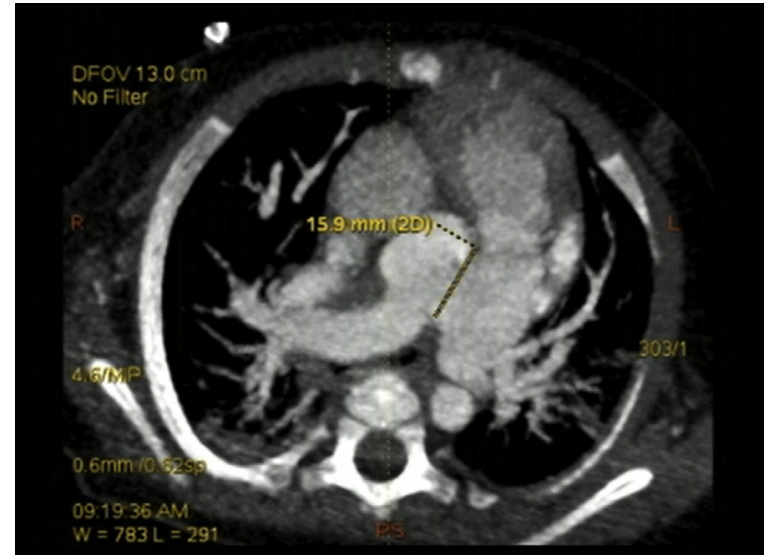

VIDEO 1. Surgical correction of Berry syndrome. This was a 5-month-old boy presenting to our center with cyanosis (Patient 15). Preoperative CT showed IAA (type A), APW and AORPA, suggesting Berry syndrome. The APW was approached via longitudinal incision through the anterior aortic wall and AORPA was reconstructed by using intra-aortic patch to redirect the flow from the MPA to RPA. IAA was then reconstructed by end-to-side anastomosis with patch augmentation. $C T$, Computed tomography; IAA, interrupted aortic arch; $A P W$, aortopulmonary window; AORPA, aortic origin of the right pulmonary artery; $M P A$, main pulmonary artery; $R P A$, right pulmonary artery. Video available at: http://www.jtcvsonline. org/article/S0022-5223(16)31683-X/addons.

pathologic findings. ${ }^{1}$ Type I is a proximal defect just above the sinus of Valsalva. Type II is a distal defect that is more cephalad on the ascending aorta (AAO). Type III is a total defect that is a combination of proximal and distal defects. Type II APW defects were further divided into 2 subtypes according to Berry. One is accompanied with a straddling RPA (IIa), which is hemodynamically related to the AAO but still maintains the continuity with the main pulmonary artery (MPA) and left pulmonary artery (LPA). This subtype of APW defect usually is extended to the middle or even right posterior wall of the AAO, which is large and backward. The other is associated with a completely separated RPA (IIb), which is both hemodynamically and anatomically related to the AAO. This subtype of APW defect is anterior and lateral on the AAO, which usually is small and forward.

\section{Operative Technique}

Once diagnosed, the patient underwent surgery. Cardiopulmonary bypass $(\mathrm{CPB})$ was used in all patients. These patients underwent surgical correction under deep hypothermia with low- flow antegrade selective cerebral perfusion (DHLF) or deep hypothermic circulatory arrest (DHCA), or mild hypothermia with low-flow antegrade selective cerebral perfusion (MHLF). The temperatures for deep hypothermia and mild hypothermia were $20^{\circ} \mathrm{C}$ and $28^{\circ} \mathrm{C}$, respectively. Blood flow for selective cerebral perfusion was 40 to $60 \mathrm{~mL} / \mathrm{kg} / \mathrm{min}$.

Surgery was performed through median sternotomy (Video 1). CPB was established by bicaval cannulas and with the insertion of 2 arterial cannulas: one on the right lateral side of the distal AAO and the other connected to the arterial tubing by a $\mathrm{Y}$ connector on the descending aorta (DAO) through the MPA and PDA. After CPB was initiated, both the LPA and RPA were snared to prevent flooding of the pulmonary circulation. After cooling to the appropriate temperature, the aorta was cross-clamped and cold blood cardioplegia was infused into the aortic root. 

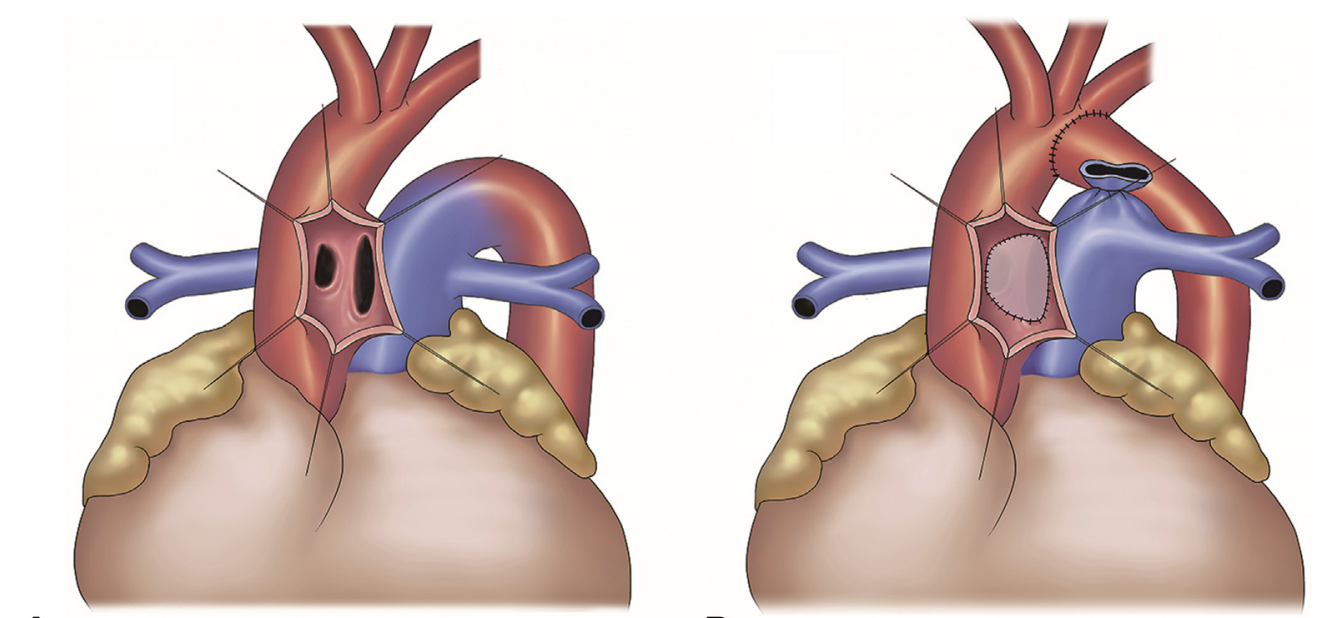

A

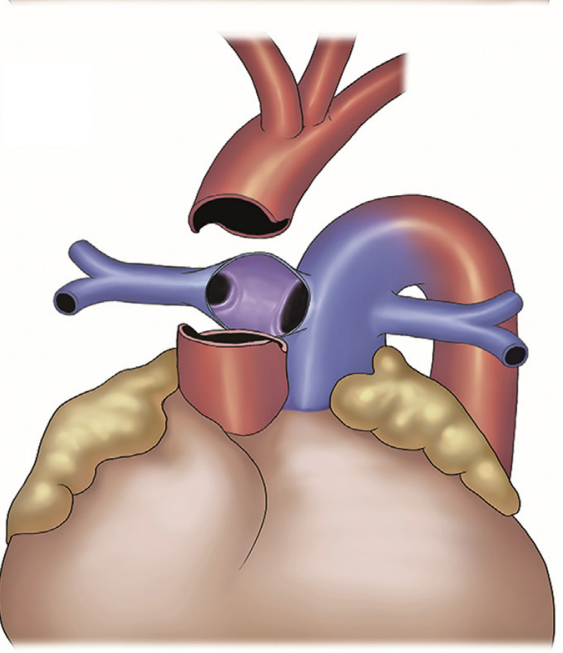

C

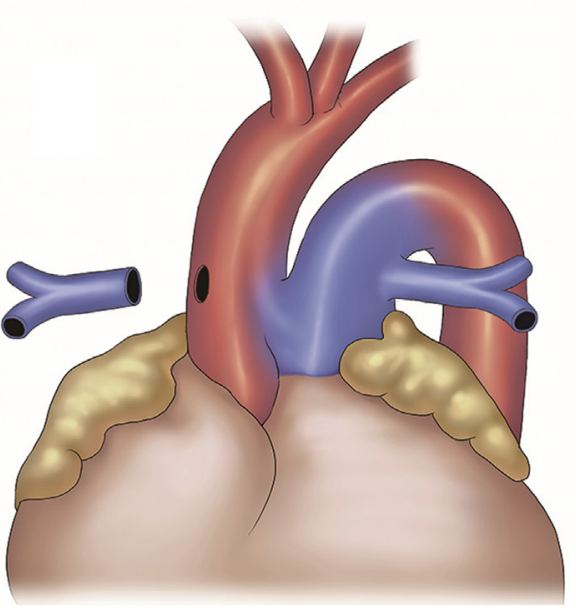

B

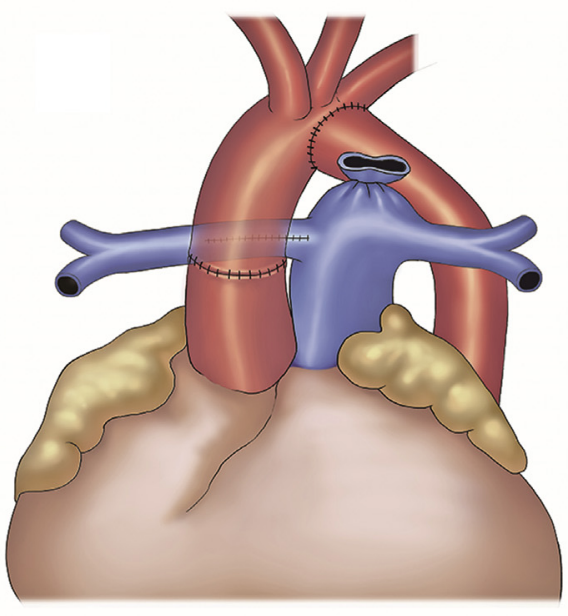

D

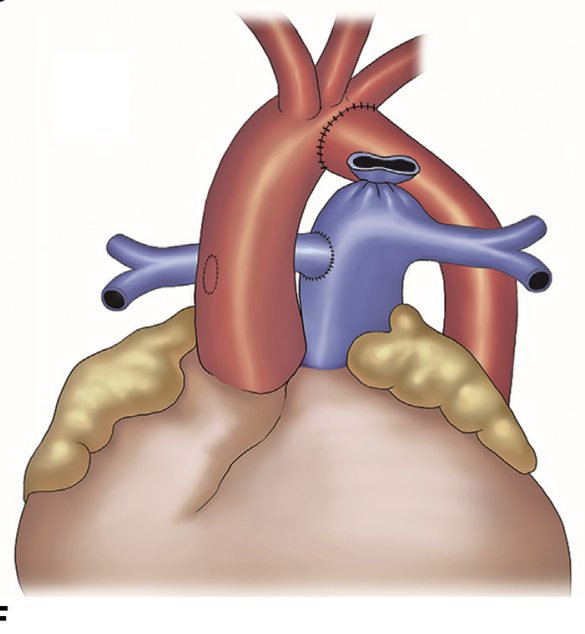

FIGURE 1. Anatomical characteristics of Berry syndrome and different methods of reconstructing the APW and AORPA. A, Berry syndrome is a combination of IAA, APW, and AORPA. B, An intra-aortic baffle is placed to redirect the flow from MPA to RPA. C-D, Aortic cuff, which is made by transecting above and below the level of RPA, constitutes the posterior wall of RPA. RPA is then closed with direct suture and AAO is repaired by end-to-end anastomosis. E-F, AORPA is excised from AAO and then directly reconstructed to the right lateral side of MPA. 

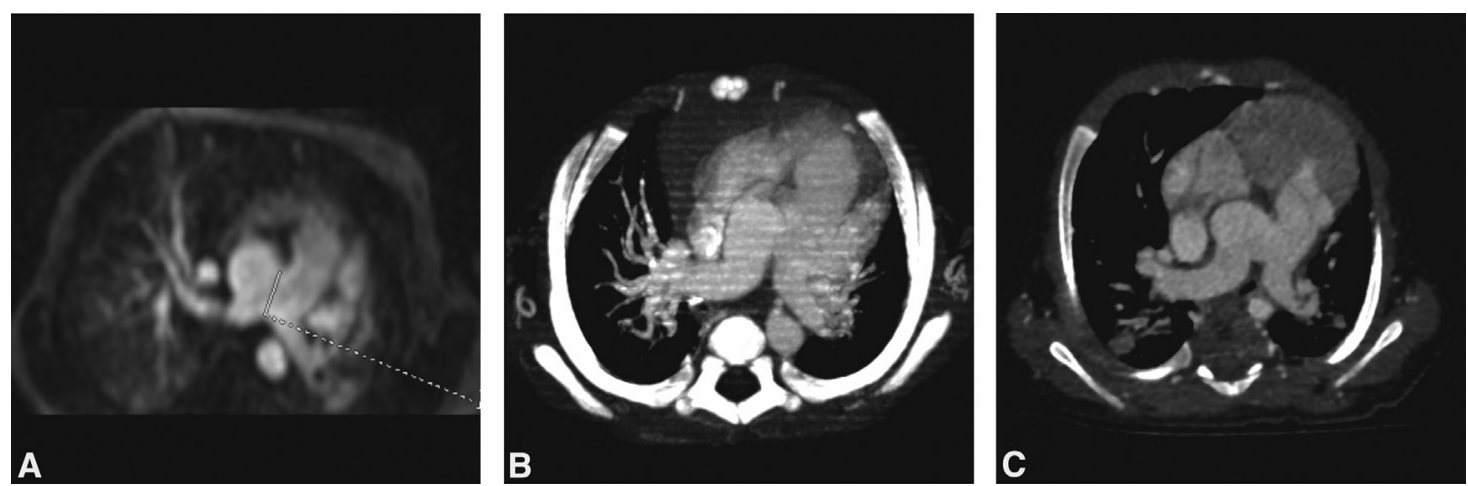

FIGURE 2. Preoperative CT or MRI angiography showing different types of the APW and AORPA in Berry syndrome. A, APW type IIa. In this type the AORPA straddles the APW but still maintains continuity with MPA and LPA. B, APW type IIb. AORPA is separated completely from the MPA. C, APW type III. APW is a total defect that combines proximal and distal defects.

The APW was then corrected with a direct incision longitudinally through the aortic anterior wall. A thorough inspection was performed in each patient to analyze the size and location of APW, origins of the coronary arteries, and the opening of RPA and LPA (Figure 1, $A$ ).

In 5 patients, a trimmed intra-aortic baffle patch (bovine pericardial patch in 3 patients, expanded polytetrafluoroethylene patch in 2 patients) was used to close the defect with a 5-0 or 6-0 continuous Prolene suture (Ethicon, Inc, Somerville, NJ), and the RPA was drained simultaneously into the side of the MPA, redirecting the flow from the MPA to the RPA (Figure 1, B). The patch inside the aorta was sewn away from the margins of the defect as well as the opening of the RPA to avoid postoperative stenosis. After the completion of the APW repair, the anterior aortic wall was closed with a direct suture.

In the remaining 11 patients, translocation of the RPA to the MPA was used. Among them, the AAO was transected above and below the level of the RPA in 5 patients, leaving its posterior aortic cuff to constitute the posterior wall of the RPA (Figure 1,C). The RPA was closed with a direct suture, and the AAO was repaired with a direct end-toend anastomosis in 4 patients or augmented with a pericardial patch in 1 patient (Figure 1, D).

In the other 6 patients, the RPA was detached from the aorta at its origin (Figure 1,E), and the MPA also was excised along the vertical incision in the APW. Both the RPA and MPA required aggressive mobilization to ensure a maximum length and flexible reconstruction. The RPA was then directly reconstructed to the right lateral side of the MPA in an end-toside anastomosis or augmented with a patch in the anterior wall if necessary (Figure $1, F$ ). In 1 patient, the RPA was brought anteriorly to the aorta before reconstruction. A pericardial patch was then used to close the aortic wall defect.

After completion of the APW and AORPA repair, the IAA was then reconstructed. The descending aortic cannula was first removed and extensive dissection of aortic arch and DAO was performed to minimize tension. In patients with DHLF and MHLF, the ascending aortic cannula was further inserted into the innominate artery. In patients with DHCA, all great arches were snared, and the aortic cannula was removed. The PDA was divided distally and all ductal tissue was resected. An incision was then made from the base of the left subclavian artery in patients with type A IAA and the left common carotid in patients with type B IAA. The DAO was anastomosed to the aortic arch by an end-to-side anastomosis with a patch augmentation in the anterior wall. In 2 type B patients, the left subclavian artery also was divided from the PDA and reanastomosed to the appropriate position in the aortic arch after the completion of arch reconstruction.

\section{Follow-up}

Patients were followed 1 month, 3 months, and 6 months after discharge, then every 6 months for the next 18 months, and then regularly every 12 months. Physical examination, echocardiography, electrocardiography, and cardiac function were evaluated in our outpatient department. If any stenosis was detected, cardiac computed tomography or magnetic resonance imaging was then performed.

\section{Statistical Analysis}

Data was analyzed with SPSS software, version 20.0 (IBM Corp, Armonk, NY). Continuous variables were presented as mean \pm standard deviation or median and range for skewness variables. Categorical variables are expressed as frequency and percentages. A Kruskal-Wallis test was used to compare the differences among the 3 groups. $P$ values of $<.05$ were considered statistically significant. Estimates for freedom from reoperation were made by the Kaplan-Meier method.

\section{RESULTS}

The median age at repair was 90.5 days (range, 8170 days). The median weight was $4.2 \mathrm{~kg}$ (range, 2.7$6.4 \mathrm{~kg}$ ). Four patients $(25.0 \%)$ underwent surgical repair in the neonatal period. Among them, prenatal diagnosis was made in 2 patients; therefore, they underwent surgery shortly after birth. Other presenting symptoms included severe pneumonia in 5 patients, cyanosis in 5 patients, and cardiac murmur on auscultation in 4 patients. Twelve patients $(75.0 \%)$ were male.

The IAA morphology was type A in 14 patients (87.5\%) and type B in 2 patients $(12.5 \%)$. The APW morphology was type IIa (Figure $2, A$ ) in 4 patients $(25.0 \%$ ), type IIb (Figure $2, B$ ) in 10 patients $(62.5 \%)$, and type III (Figure 2, C) in 2 patients (12.5\%). Patient demographic data are summarized in Table 1.

Preoperative mechanical ventilation was required in 2 patients $(12.5 \%)$. These patients had demonstrated left bronchi compression secondary to the dilated RPA. Prostaglandins were not administered in the preoperative period. 
TABLE 1. Summary of demographic characteristics

\begin{tabular}{|c|c|c|c|c|c|c|}
\hline Patient & Age, $d$ & Weight, kg & IAA type & APW type & APW size, $\mathbf{m m}$ & RPA reconstruction method \\
\hline 1 & 8 & 4.2 & A & IIa & 9.5 & 3 \\
\hline 2 & 134 & 5.2 & A & IIa & 12.5 & 1 \\
\hline 3 & 103 & 3.9 & A & $\mathrm{IIb}$ & 6.8 & 2 \\
\hline 4 & 110 & 6.4 & A & $\mathrm{IIb}$ & 7.8 & 2 \\
\hline 5 & 63 & 4.5 & A & IIa & 12 & 1 \\
\hline 6 & 53 & 4.2 & A & $\mathrm{IIb}$ & 7.9 & 2 \\
\hline 7 & 112 & 3.6 & A & $\mathrm{IIb}$ & 9.2 & 2 \\
\hline 8 & 119 & 5.0 & A & III & 12.0 & 3 \\
\hline 9 & 120 & 6.0 & A & $\mathrm{IIb}$ & 9.9 & 1 \\
\hline 10 & 14 & 4.0 & A & $\mathrm{IIb}$ & 6.5 & 3 \\
\hline 11 & 78 & 3.9 & B & $\mathrm{IIb}$ & 11.6 & 3 \\
\hline 12 & 43 & 2.7 & A & $\mathrm{IIb}$ & 9 & 1 \\
\hline 13 & 25 & 3.6 & B & $\mathrm{IIb}$ & 10.9 & 2 \\
\hline 14 & 21 & 3.3 & A & $\mathrm{IIb}$ & 10.2 & 2 \\
\hline 15 & 170 & 6.2 & A & IIa & 14.9 & 1 \\
\hline 16 & 156 & 5 & A & III & 12.5 & 3 \\
\hline
\end{tabular}

Reconstruction method: intra-aortic baffle $=1, \mathrm{RPA}$ detachment $=2$, RPA arterioplasty with aortic cuff $=3$. IAA, Interrupted aortic arch; $A P W$, aortopulmonary window; $R P A$, right pulmonary artery.

The median CPB and aortic crossclamp time was 114.5 minutes (range, 79-260 minutes) and 68.5 minutes (range, 46-147 minutes), respectively. Seven patients $(43.8 \%)$ underwent surgical repair under DHLF, 7 patients $(43.8 \%)$ under DHCA, and 2 patients $(12.5 \%)$ under MHLF. The median time for antegrade selective cerebral perfusion and circulatory arrest was 69 minutes (range, 45-116 minutes) and 22 minutes (range, 17-43 minutes), respectively. No differences were identified among the $3 \mathrm{RPA}$ reconstruction subgroups in terms of CPB or aortic crossclamp time $(P=.567$ and .992 , respectively).

\section{Early Postoperative Outcomes}

Of 16 patients, $2(12.5 \%)$ died in the hospital. Patient 5 had severe pneumonia and congestive heart dysfunction before surgery and received preoperative mechanical ventilation for airway compression. After surgical repair, he still suffered severe hypoxemia and prolonged respiratory infection. No residual stenosis could be detected on postoperative TTE. Although high-frequency ventilation with antibiotic therapy was applied, the patient died of multiorgan dysfunction on postoperative day 26. The hemodynamics of patient 10 were unstable soon after surgery. Emergency exploratory sternotomy was performed, and bleeding at the anastomosis site was found. He died on postoperative day 1 despite immediate hemostasis.

The mean time for mechanical ventilation was $128.7 \pm 62.9$ hours (range, 45-240 hours), and the mean time for intensive care unit stay was $12.4 \pm 5.9$ days (range, 5-25 days). Delayed sternal closure was performed in 10 patients $(62.5 \%)$. Peritoneal dialysis was required in 4 patients $(25.0 \%)$. Four patients with postoperative stridor, hoarseness, and weak cry underwent fiberoptic laryngobronchoscopy. Left vocal cord paralysis was found in 2 patients, suggesting recurrent laryngeal nerve injury. No feeding difficulties occurred.

Two patients had pulmonary hypertensive crisis immediately after cessation of CPB, and hemodynamics could not be maintained. Pulmonary-to-systemic blood pressure ratio was 1.0. CPB was applied once again and inhaled iloprost solution was administered. Pulmonary-to-systemic blood pressure ratio decreased to 0.4 to 0.5 after the cessation of CPB. Postoperative pulmonary vasodilation therapy was administered to all patients. In the first 3 days after surgery, a strategy for combination usage of inhaled iloprost solution (500 ng/kg/dose, 6-8 times a day) and oral bosentan ( $2 \mathrm{mg} / \mathrm{kg} / \mathrm{dose}$, twice a day) was used. During these days, the frequency of iloprost solution was decreased gradually. Patient 16 had pulmonary hypertension crisis 5 days after surgery. The hemodynamics of this patient were suddenly unstable, with heart rate decreasing to 50 to 60 beats per minute, blood pressure decreasing to $50 / 20 \mathrm{~mm} \mathrm{Hg}$, and peripheral oxygen saturation unable to detect. Treprostinil was administered to decrease the pulmonary artery resistance. All patients underwent TTE before discharge to assess the pulmonary arterial pressure indirectly by measuring the tricuspid regurgitation gradient. Six patients were on bosentan after discharge. Three months later, their tricuspid regurgitation gradient decreased below $40 \mathrm{mmHg}$, and bosentan was then discontinued.

Postoperative RPA stenosis caused by the compression from the AAO was identified in patient 11 . This patient previously received RPA arterioplasty with aortic cuff and a 


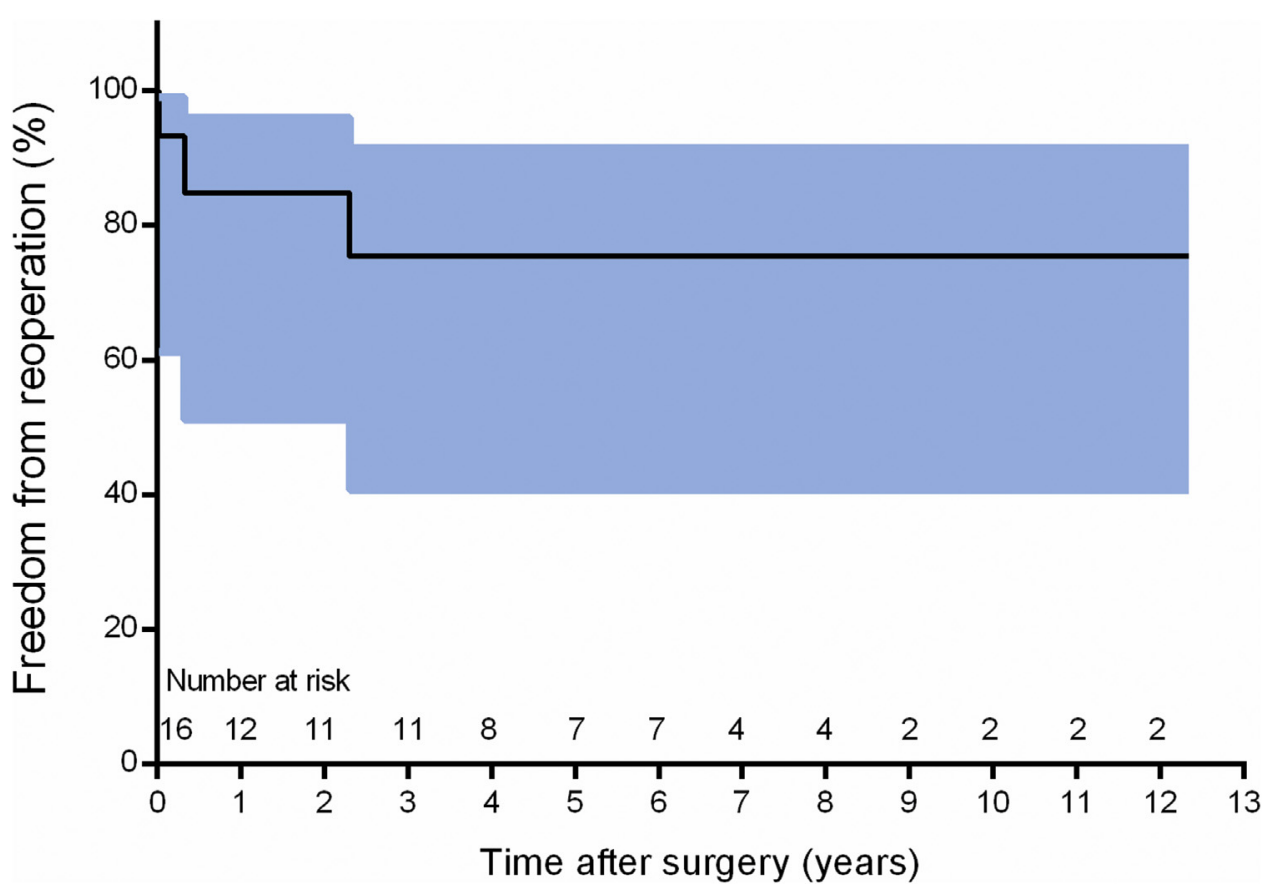

FIGURE 3. Kaplan-Meier estimates of freedom from reoperation after surgical repair of Berry syndrome. The shaded area indicates $95 \%$ confidence limits.

direct end-to-end aortic anastomose. Lecompte maneuver was performed on postoperative day 7 to release the compression of the RPA.

\section{Follow-up and Reoperations}

Mean follow-up time was $4.8 \pm 3.7$ years (range, 0.212.3 years). Follow-up death occurred in 1 patient $(7.1 \%)$. Patient 13 was readmitted to our department because of dyspnea at 2 months after discharge. TTE showed RPA gradient was $30 \mathrm{~mm} \mathrm{Hg}$ but left ventricular ejection fraction couldn't be evaluated. High dose of inotropes and mechanical ventilation was applied. During the second TTE 1 day after admission, the patient's vital sign was suddenly unstable. The patient died before we could do further examination to find the cause. Freedom from reoperation was $84.8 \%, 75.4 \%$, and $75.4 \%$, respectively at 1 , 5 , and 10 years after surgery (Figure 3 ).

Reoperations were required in 2 patients during the follow-up period. Both patients underwent RPA arterioplasty with aortic cuff previously. Patient 1 suffered dyspnea and cyanosis at 4 months after discharge. TEE showed an aortic arch stenosis at the anastomotic site with a pressure gradient of $64.0 \mathrm{~mm} \mathrm{Hg}$ as well as RPA stenosis due to the compression by the shortened and enlarged AAO. Aortic arch reconstruction and RPA arterioplasty with bovine pericardial patch augmentation was then performed. Patient 8 had a moderate RPA stenosis at 2 years after discharge. Balloon dilation angioplasty of RPA was first performed to relieve the obstruction; however, RPA restenosis was identified 1 month later. This patient had to undergo surgical reoperation of RPA enlargement with bovine pericardial patch. Both of these patients showed no evidence of restenosis at the most recent follow-up.

No other patients suffered from postoperative supravalvar aortic stenosis or aortic arch stenosis during follow-up period. At the last follow-up, all patients were in good cardiac function (New York Heart Association functional class I). Left ventricular ejection fraction was $69.6 \pm 4.5 \%$ and RPA gradient was $21.4 \pm 8.0 \mathrm{~mm} \mathrm{Hg}$. Tricuspid regurgitation was trivial in 9 patients $(69.2 \%)$ and mild in 4 patients $(30.8 \%)$.

\section{DISCUSSION}

Berry syndrome is a rare congenital heart disease with a combination of 3 different anomalies. The literature consists of anecdotal case studies performed by different surgeons throughout the world (Table 2). ${ }^{2-5,8-17}$ Most centers advocate one-stage surgery in the neonatal period, although Ghelani and colleagues ${ }^{5}$ suggested that a staged repair should be considered in premature infants or small-forgestational-age infants. We also recommend surgical correction should be performed as early as possible.

The optimal surgical treatment of APW and AORPA is still controversial. Three different surgical corrections have been discussed by different centers. In 1990, our institution first described a method of intra-aortic baffle patch to repair both the APW and AORPA. ${ }^{18}$ This method has 3 
TABLE 2. Summary of recent English literatures on Berry syndrome

\begin{tabular}{|c|c|c|c|c|c|c|c|}
\hline $\begin{array}{c}\text { First author } \\
\text { and years } \\
\text { published }\end{array}$ & $\begin{array}{c}\text { No. of } \\
\text { patients }\end{array}$ & $\begin{array}{c}\text { Age at } \\
\text { surgery }\end{array}$ & Sex & $\begin{array}{c}\text { Genetic } \\
\text { anomaly }\end{array}$ & $\begin{array}{c}\text { RPA } \\
\text { reconstruction } \\
\text { method } \\
\end{array}$ & Outcome & $\begin{array}{c}\text { Follow-up } \\
\text { time }\end{array}$ \\
\hline $\begin{array}{l}\text { Alsoufi and } \\
\text { colleagues, } 2016^{4}\end{array}$ & $3 *$ & - & - & - & Aortic cuff & $\begin{array}{c}1 \text { patient required } \\
\text { reoperation for } \\
\text { AAO and } \\
\text { branch PA } \\
\text { stenosis }\end{array}$ & - \\
\hline $\begin{array}{l}\text { Remon and } \\
\text { colleagues, } 2016^{8}\end{array}$ & 1 & Not done & & Trisomy 13 & - & - & - \\
\hline $\begin{array}{l}\text { Liu and } \\
\quad \text { colleagues, } 2015^{9}\end{array}$ & 1 & $13 \mathrm{mo}$ & M & - & $\begin{array}{c}\text { Aortic flap and } \\
\text { homologous } \\
\text { PA patch }\end{array}$ & Uneventful & $15 \mathrm{mo}$ \\
\hline $\begin{array}{l}\text { Ghelani and } \\
\text { colleagues, } 2015^{5}\end{array}$ & 1 & $\begin{array}{l}\text { PA banding on } \\
2 \mathrm{~d} \text {; definitive } \\
\text { repair on } 13 \mathrm{~d}\end{array}$ & $\mathrm{~F}$ & - & $\begin{array}{c}\text { Intra-aortic patch } \\
\text { with aortic root } \\
\text { enlargement }\end{array}$ & Mild RPA stenosis & $3 \mathrm{mo}$ \\
\hline $\begin{array}{l}\text { Jayaram and } \\
\text { colleagues, } 2013^{10}\end{array}$ & 1 & $7 \mathrm{~d}$ & $\mathrm{~F}$ & $\begin{array}{r}\text { 102-kb deletion } \\
\text { within } 9 \mathrm{p} 24.2\end{array}$ & Intra-aortic patch & - & - \\
\hline $\begin{array}{l}\text { Morito and } \\
\text { colleagues, } 2011^{11}\end{array}$ & 1 & $10 \mathrm{~d}$ & $\mathrm{~F}$ & - & Intra-aortic patch & Uneventful & - \\
\hline $\begin{array}{l}\text { Mannelli and } \\
\text { colleagues, } 2011^{12}\end{array}$ & 1 & $1 \mathrm{mo}$ & M & - & Intra-aortic patch & Uneventful & $8 \mathrm{mo}$ \\
\hline $\begin{array}{l}\text { Konstantinov and } \\
\text { colleagues, } 2010^{13}\end{array}$ & $1^{*}$ & $3 d$ & $\mathrm{~F}$ & - & Unknown & Uneventful & $24.1 \mathrm{y}$ \\
\hline \multirow[t]{2}{*}{$\begin{array}{l}\text { Park and } \\
\text { colleagues, } 2008^{14}\end{array}$} & 2 & $4 \mathrm{mo}$ & M & - & $\begin{array}{l}\text { Aortic cuff with } \\
\text { pericardial patch }\end{array}$ & $\begin{array}{c}\text { RPA stenosis; } \\
\text { relieved by } \\
\text { balloon } \\
\text { angioplasty }\end{array}$ & $18 \mathrm{mo}$ \\
\hline & & $8 \mathrm{~d}$ & $\mathrm{~F}$ & - & Aortic cuff & Uneventful & $1 \mathrm{y}$ \\
\hline $\begin{array}{l}\text { Konstantinov and } \\
\text { colleagues, } 2006^{3} \dagger\end{array}$ & $5^{*}$ & Neonatal & - & - & - & - & - \\
\hline Fong, $2006^{15}$ & 1 & $3 d$ & $\mathrm{~F}$ & - & Unknown & $\begin{array}{l}\text { Good cardiac } \\
\text { function with } \\
\text { mild residual } \\
\text { CoA and RPA } \\
\text { stenosis }\end{array}$ & $1 \mathrm{y}$ \\
\hline $\begin{array}{l}\text { Senzaki and } \\
\text { colleagues, } 2003^{16}\end{array}$ & 1 & $6 \mathrm{~d}$ & M & - & Aortic cuff & - & $40 \mathrm{~d}$ \\
\hline Backer, $2002^{2}$ & $1 * \ddagger$ & $30 \mathrm{~d}$ & - & - & RPA detachment & $\begin{array}{c}\text { Die of sepsis on } \\
\text { postoperative } \\
\text { day } 16\end{array}$ & - \\
\hline Sharma, $2002^{17}$ & 1 & Not done & F & Trisomy 13 & - & - & - \\
\hline
\end{tabular}

RPA, Right pulmonary artery; $A A O$, ascending aorta; $P A$, pulmonary artery; $M$, male; $F$, female; $C o A$, coarctation of aorta. *Included in a broad spectrum of patients with disease such as aortopulmonary window (APW) or IAA. †CHSS database. $\ddagger$ Two other cases have been previous reported by Berry and colleagues. ${ }^{1}$

advantages. First, it is relatively easy to perform. Second, it maintains the confluence between the MPA and RPA with no incision in the posterior aortic wall. Third, this procedure also largely reduces the risk of bleeding for a minimum incision and an anterior suture in the AAO. When this procedure is performed, the intra-aortic patch should be trimmed precisely to prevent obstruction of the left ventricular outflow and the RPA. Some authors, however, consider the size and growth potential of the baffle patch as 2 drawbacks for this procedure, especially in neonates. ${ }^{19,20}$ In our series, no patients developed supravalvar or RPA obstruction in the follow-up period, although 1 patient died of severe respiratory infection. They underwent surgery at a relatively older age, which may be the reason why no supravalvar obstruction was detected.

Among these 5 patients with intra-aortic baffle technique, 3 of them were type IIa APW defects and the remaining 2 were type IIb defects. In our experience, the intra-aortic 
baffle patch can be performed in all type IIa APW defects. Considering the pathologic characteristics in this subtype and that the APW is distal and RPA is straddling the aorta and the pulmonary trunk, the distance between the APW and RPA is close enough for patch repair. ${ }^{11}$ The patch will form the lateral and posterior wall of the aorta, not just cross the cavity. At the same time, the RPA preserves its continuity with the MPA, and the patch will not influence the origin of the RPA. When it comes to Type IIb APW defects, however, supravalvar aortic stenosis may occur because the APW usually is forward and the origin of the RPA will move backward to the right posterior wall of the aorta. Theoretically, the distance between the APW and RPA may be too far for patch repair and the intra-aortic patch could lead to a reduction in aortic diameter and stenosis at the RPA origin. However, contrary to our previous expectation, supravalvar aortic stenosis was not found in 2 Type IIb patients. Mannelli and colleagues ${ }^{12}$ also described several cases of intra-aortic patch repair in type IIb patients with no complications. Unfortunately, we are now unable to determine the potential risk factors for this procedure due to the limited number of our patients and the short term of follow-up.

RPA arterioplasty with aortic cuff is another surgical method to maintain the continuity of the RPA with the MPA; however, the aorta has to be transected, thus increasing the risk of bleeding in the posterior aortic wall, which often is quite difficult to find. Also the AAO should be shortened if a direct end-to-end anastomosis is performed to repair the aortic wall defect, thus causing obstruction of the RPA and left main bronchus when pressed by the aorta posteriorly. In this circumstance, we would perform Lecompte maneuver to shift the pulmonary arteries in front of AAO. At our institution, 1 patient died on postoperative day 1 in this group. Two patients received reoperation for RPA stenosis caused by the compression by aorta, and 1 patient underwent RPA reintervention for its origin stenosis. Reoperation rate of this surgical method is much greater than that of the other 2 methods. We reviewed the recent literatures and found that at least 2 of 6 patients $(33.3 \%)$ who underwent this procedure developed RPA stenosis that required reinterventions. ${ }^{4,14}$ In our experience, this surgical procedure is not as successful and should not be the preferred approach. If the aortic cuff is large enough for direct suture of RPA to ensure its growth potential, patch augmentation of the posterior wall of the aorta is required to ensure an adequate aortic length to relieve the tension of the anastomosis. ${ }^{3,4}$

RPA detachment is another surgical method to translocate the RPA to the MPA. This procedure is now the most frequently performed in patients with isolated AROPA. ${ }^{21}$ As long as the mobilization of the RPA is feasible, the RPA can be directly anastomosed to MPA with only an anterior patch augmentation to reduce the tension. If the distance is too far for direct suture, a trapdoor flap from the anterolateral wall of the MPA has been described by Chang and colleagues ${ }^{22}$ to ensure a native tissue-to-tissue anastomosis with growth potential. With the application of this procedure, it is easier to transfer the RPA anteriorly to the aorta to decrease its compression by the airway, and the transposed RPA would be in a more accessible position for further reconstruction. Anterior translocation of the RPA is not included in a standard protocol but is selected according to surgeon preference. When compared with an intraaortic patch, RPA detachment is more flexible in RPA reconstruction, for it can be performed in all patients with Berry syndrome, no matter the origin of the RPA or the size of the APW; however, this procedure is more difficult to perform compared with the intra-aortic baffle and destroys the confluence between the MPA and RPA.

The surgical treatment of IAA in Berry syndrome is repaired the same as we do in isolated IAA; however, the surgical outcome of arch reconstruction plays an essential role in Berry syndrome. ${ }^{3,14}$ The distal obstruction of the aortic arch can cause the proximal dilation of the AAO, thus compressing the RPA and left main bronchus. ${ }^{13}$ Under this circumstance, the optimal arch reconstruction method would be patch augmentation to eliminate postoperative arch stenosis.

\section{Limitations}

There are several limitations of the present study. Although Berry syndrome is a rare congenital anomaly with only isolated cases reported, this is still a retrospective analysis of a single center with a relatively small group of patients. Our series also tended toward older patients, mainly because of the delayed presentation of some patients. Results may be affected by selection bias. Longer follow-up data are required to evaluate postoperative supravalvar aortic stenosis and RPA stenosis. We also lack strong evidence to determine the precise indications and contraindications for intra-aortic patch. Given the small size of our patient cohort and the small number of events, no risk factors were identified.

\section{CONCLUSIONS}

One-stage primary repair of Berry syndrome has achieved acceptable outcomes in recent years. The classification of this complex malformation is quite important for different surgical choices. Reoperations are mainly due to aortic or RPA stenosis. The reoperation rate is much higher when RPA arterioplasty is performed with an aortic cuff.

\section{Conflict of Interest Statement}

Authors have nothing to disclose with regard to commercial support. 


\section{References}

1. Berry TE, Bharati S, Muster AJ, Idriss FS, Santucci B, Lev M, et al. Distal aortopulmonary septal defect, aortic origin of the right pulmonary artery, intact ventricular septum, patent ductus arteriousus and hypoplasia of the aortic isthmus: a newly recognized syndrome. Am J Cardiol. 1982;49:108-16.

2. Backer CL, Mavroudis C. Surgical management of aortopulmonary window: a 40-year experience. Eur J Cardiothorac Surg. 2002;21:773-9.

3. Konstantinov IE, Karamlou T, Williams WG, Quaegebeur JM, del Nido PJ, Spray TL, et al. Surgical management of aortopulmonary window associated with interrupted aortic arch: a Congenital Heart Surgeons Society study. J Thorac Cardiovasc Surg. 2006;131:1136-41.e1132.

4. Alsoufi B, Schlosser B, McCracken C, Kogon B, Kanter K, Border W, et al. Current outcomes of surgical management of aortopulmonary window and associated cardiac lesions. Ann Thorac Surg. 2016;102:608-14.

5. Ghelani SJ, Quinonez LG, Rathod RH. Prenatal diagnosis and management of Berry syndrome, a rare conotruncal anatomy. Circulation. 2015;132: 1593-4.

6. Celoria GC, Patton RB. Congenital absence of the aortic arch. Am Heart J. 1959; 58:407-13.

7. Mori K, Ando M, Takao A, Ishikawa S, Imai Y. Distal type of aortopulmonary window. Report of 4 cases. Br Heart J. 1978;40:681-9.

8. Remon JI, Briston DA, Stern KW. Berry syndrome: the importance of genetic evaluation before surgical intervention. Cardiol Young. 2016;26:188-90.

9. Liu Y, Cheng L, Qian X, Zhu H, Duan W, Yu S, et al. Surgical correction of anomalous origin of one pulmonary artery without grafts in infants. J Card Surg. 2015; 30:85-91.

10. Jayaram N, Knowlton J, Shah S, Gelatt M, Lofland G, Raghuveer G. Berry syndrome: a possible genetic link. Pediatr Cardiol. 2013;34:1511-3.

11. Morito H, Masuzawa A, Kobayashi J, Takeuchi K. One-stage surgical repair for Berry syndrome with preoperative diagnosis by 3-dimensional ct. World $\mathrm{J} \mathrm{Pe}$ diatr Congenit Heart Surg. 2011;2:491-4.

12. Mannelli L, Mosca R, Henry G, Srichai-Parsia MB. A case of Berry syndrome type 2b. Congenit Heart Dis. 2011;6:389-92.
13. Konstantinov IE, Oka N. d'Udekem Y, Brizard CP. Surgical repair of aortopulmonary window associated with interrupted aortic arch: long-term outcomes. J Thorac Cardiovasc Surg. 2010;140:483-4.

14. Park SY, Joo HC, Youn YN, Park YH, Park HK. Berry syndrome: two cases of successful surgical repair. Circ J. 2008;72:492-5.

15. Fong NC, Kong CT, Mak WY, Shiu YK, Lee SY, Chow CB, et al. Early detection of Berry syndrome in a newborn with differential cyanosis. Chin Med J (Engl). 2006;119:1485-8.

16. Senzaki H, Asano H, Masutani S, Matunaga T, Ishido H, Taketatu M, et al Anomalous origin of the left coronary artery from the main pulmonary artery associated with Berry syndrome. J Thorac Cardiovasc Surg. 2003;126: 1645-7.

17. Sharma J, Saleh M, Das BB. Berry syndrome with trisomy 13. Pediatr Cardiol. 2002;23:205-9.

18. Ding WX, Su ZK, Cao DF, Jonas RA. One-stage repair of absence of the aortopulmonary septum and interrupted aortic arch. Ann Thorac Surg. 1990;49:664-6.

19. Codispoti M, Mankad PS. One-stage repair of interrupted aortic arch, aortopulmonary window, and anomalous origin of right pulmonary artery with autologous tissues. Ann Thorac Surg. 1998;66:264-7.

20. Burke RP, Rosenfeld HM. Primary repair of aortopulmonary septal defect, interrupted aortic arch, and anomalous origin of the right pulmonary artery. Ann Thorac Surg. 1994:58:543-5.

21. Cho S, Kim WH, Choi ES, Lee JR, Kim YJ. Surgical results of anomalous origin of one pulmonary artery branch from the ascending aorta. Pediatr Cardiol. 2015; 36:1532-8.

22. Chang YH, Sung SC, Kim H, Lee HD. Anterior translocation of the right pulmonary artery for relief of airway compression in the repair of distal aortopulmonary window and interrupted aortic arch. Ann Thorac Surg. 2012; 93:e159-61.

Key Words: aortopulmonary window, aortic origin of the right pulmonary artery, interrupted aortic arch 